\title{
O princípio da capacidade contributiva sob a ótica do imposto de renda da pessoa física ${ }^{1}$
}

\author{
Juliane Almudi de Freitas ${ }^{2}$
}

\begin{abstract}
Resumo
Tendo em vista que a sociedade é formada por cidadãos com diferentes níveis de riqueza, destaca-se o princípio da capacidade contributiva, garantido a nível constitucional, como instrumento capaz de realizar a Justiça Fiscal. Nesse contexto, o princípio da capacidade contributiva é o princípio informador da maioria impostos, entre eles o imposto sobre a renda e proventos de qualquer natureza. A fim de que o referido tributo observe a capacidade contributiva, é preciso que o mesmo seja progressivo. A consecução de tal desiderato somente é possível através da conjugação de três elementos, ou seja, a base de cálculo, a alíquota e a parcela a deduzir.
\end{abstract}

Palavras-Chave: Imposto de renda pessoa física; Princípio da capacidade contributiva; Progressividade.

\section{Introdução}

Na sociedade temos pessoas com diferentes graus de riqueza. Por isso, para que um imposto seja justo, ele não se traduzir em iguais valores para contribuintes com rendas diferentes.

É neste contexto que surge o princípio da capacidade contributiva, para amoldar os impostos conforme o grau de riqueza dos cidadãos. É justo que tem muito, pague proporcionalmente mais imposto do que tem pouco.

O princípio da capacidade contributiva, portanto, está intimamente ligado ao princípio da igualdade, representando um importante mecanismo de Justiça fiscal.

No que tange ao imposto sobre a renda e proventos de qualquer natureza,o princípio da capacidade contributiva é implementado através do critério da progressividade. Este pressupõe que aquele contribuinte que aufere rendimentos mais expressivos deve ser com alíquotas maiores do que aquele que tem rendimentos menores. Como se verá, para

\footnotetext{
1 Trabalho apresentado como requisito parcial da nota referente ao 4을 Bimestre, referente à disciplina de Direito Tributário, do curso de graduação em Direito, da Universidade Estadual de Londrina.

2 Bacharel em Direito pela Universidade Estadual de Londrina. starsbr@yahoo.com.br.
} 
que esse critério seja realmente implementado é mister a conjugação de três elementos, quais sejam: a base de cálculo, a alíquota e as deduções permitidas em lei.

\section{Regra-matriz do imposto de renda pessoa física}

A Constituição Federal em Título VI, Capítulo I, denominado Do Sistema Tributário Nacional, estabelece a distribuição da competência tributária entre os entes da federação, quais sejam, União, Estados, Distrito Federal e Municípios. Ademais, dá os traços gerais relativos a cada tributo.

No caso do imposto sobre a renda e proventos de qualquer natureza, a Carta Magna define em seu artigo 153, inciso III, que a competência para sua criação pertence à União. Mais adiante, no inciso I, do parágrafo segundo deste mesmo dispositivo determina que o referido imposto será informado pelos critérios da generalidade, da universalidade e da progressividade, na forma da lei.

É tarefa reservada à lei infraconstitucional dar contornos mais nítidos acerca da hipótese de incidência da cada tributo. Em matéria de imposto de renda, pode-se dizer que o Código Tributário Nacional, especialmente em seus artigos 43 a 45, a Lei no 9.250/95 e leis suas posteriores alterações, assim como o Decreto-lei no 3.000/99 tratam de desenhar a sua regra matriz de incidência fiscal e de pormenorizar o referido imposto. Vejamos, a seguir, a estrutura desta:

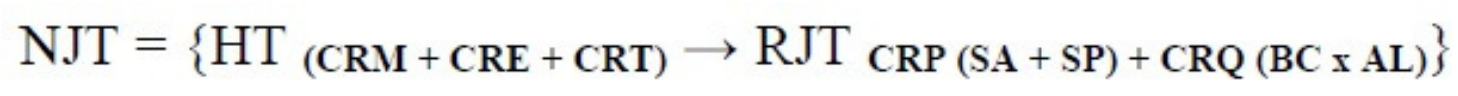

Tabela 1 - Norma jurídica tributária (NJT)

\begin{tabular}{|c|c|}
\hline HT: hipótese tributária & RJT: relação jurídica tributária \\
\hline CRM: critério material & CRP: critério pessoal \\
& - sa: sujeito ativo \\
CRE: critério espacial & CRQ: sujeito passivo \\
\hline
\end{tabular}




\begin{tabular}{|l|l|}
\hline CRT: critério temporal & - bc: base de cálculo \\
& - al: alíquota \\
\hline
\end{tabular}

\subsection{Critério material}

Depreende-se do contido no artigo 153, inciso III, da Constituição Federal, bem como do artigo 43, incisos I e II, do Código Tributário Nacional, que o critério material da norma jurídica do imposto de renda é, de modo sucinto, auferir renda e/ou proventos de qualquer natureza.

\subsection{Critério espacial}

O critério espacial consiste-se no território nacional, mesmo que a receita ou rendimento sejam oriundos do exterior (artigo 43, parágrafo 2ํㅡ, Código Tributário Nacional).

\subsection{Critério temporal}

O critério temporal é o momento em que o critério material considera-se ocorrido. Aquele se perfaz quando da aquisição da disponibilidade econômica ou jurídica.

Na hipótese dos contribuintes que têm seu imposto retido na fonte, o critério temporal é mensal, ou seja, a data do recebimento da renda ou provento. Nos demais casos, o critério temporal se verifica na data em que a pessoa auferiu renda.

\subsection{Critério pessoal}

Nos termos do artigo 150, inciso III, da Magna Carta, o sujeito ativo do tributo em comento é a União, todavia, cumpre ressaltar que a Secretaria da Receita Federal é o órgão responsável pela arrecadação e fiscalização do imposto.

O sujeito passivo, por seu turno, é a pessoa física que aufere a renda e/ou os proventos de qualquer natureza. Em que pese a redação do artigo 45, do Código Tributário Nacional mencione o termo responsável, em se tratando de imposto de renda retido na fonte, a fonte pagadora que promove a retenção do imposto funciona na qualidade de 
substituto, uma vez que o valor recolhido a título de imposto não corre as suas expensas, sendo retirado da própria remuneração do empregado.

\subsection{Critério quantitativo}

O critério quantitativo encontra-se localizado no conseqüente da Regra Matriz de Incidência Fiscal. O mesmo é composto pelo binômio base de cálculo e alíquota, através dos quais é possível a obtenção do quantum debeatur, ou seja, a quantia devida a título de tributo ao sujeito ativo da relação jurídica tributária.

De acordo com as lições de Paulo de Barros Carvalho (2005, p. 331-332), a base de cálculo "se destina, primordialmente, a dimensionar a intensidade do comportamento inserto no núcleo do fato jurídico, para que, combinando-se à alíquota, seja determinado o valor da prestação pecuniária." Complementa o referido mestre que a base de cálculo possui três importantes funções distintas: “a) medir as proporções reais do fato; b) compor a específica determinação da dívida; e c) confirmar, infirmar ou afirmar o verdadeiro critério material da descrição contida no antecedente da norma."

Por seu turno, a alíquota é um componente aritmético para a determinação da quantia que será objeto da prestação pecuniária. Sua presença é imprescindível para que conjugada à base de cálculo possa se chegar a quantia que será objeto da prestação pecuniária.

No caso do imposto de renda pessoa física, a base de cálculo na declaração de ajuste anual será "a diferença entre a soma dos rendimentos tributáveis recebidos durante o ano-calendário, exceto os isentos, não-tributáveis, tributáveis exclusivamente na fonte ou sujeitos à tributação definitiva, e as deduções permitidas pela legislação" (art. 8o, da Lei no 9.250/95).

O dispositivo trata, dentre outros assuntos, da isenção. Esta, segundo o ilustre professor Paulo de Barros Carvalho (2005, p. 188), se dá no plano da legislação ordinária e "pressupõe um encontro normativo, em que ela, regra de isenção opera como expediente redutor do campo de abrangência dos critérios da hipótese ou da conseqüência da regramatriz do tributo". Como exemplo de rendimentos enquadráveis nesta categoria podemos citar: Rendimentos decorrentes de despedida ou rescisão de contrato de trabalho, FGTS e pedido de demissão voluntária; as aposentadorias, pensões, rendimentos da transferência 180

ReVista de Direito Público, LondRINA, V. 2, N. 2, P. 177-188, MAIO/Ago. 2007. 
para a reserva remunerada ou reforma, do contribuinte com 65 anos de idade, até o valor de $\mathrm{R} \$ 1.257,12$ por mês, etc.

Da base de cálculo poderão ser feitas algumas deduções, como, por exemplo, despesas com exames laboratoriais, serviços radiológicos, aparelhos ortopédicos, próteses ortopédicas e dentárias, pagamentos de despesas com instrução do contribuinte e de seus dependentes, contribuições da Previdência Social da União, Estados, Distrito Federal e Municípios, importâncias pagas a título de pensão alimentícia, etc.

Em relação às alíquotas, no atual imposto de renda pessoa física temos duas alíquotas:

Tabela 2 - Tabela progressiva para o cálculo anual do imposto de renda de pessoa física para o exercício de 2006, ano-calendário de 2005.

\begin{tabular}{|c|c|}
\hline Base de cálculo em RS & Alíquota \% \\
\hline Até $13.968,00$ & - \\
\hline De 13.968 .01 até $27.912,00$ & 15,0 \\
\hline Acima de $27.912,00$ & 27,5 \\
\hline
\end{tabular}

Tabela 3 - Tabela Progressiva referente ao mês de fevereiro de 2006, para o cálculo do imposto de renda retido na fonte.

\begin{tabular}{|c|c|}
\hline Base de cálculo em RS & Alíquota \% \\
\hline Até $13.968,00$ & - \\
\hline De 13.968 .01 até $27.912,00$ & 15,0 \\
\hline Acima de $27.912,00$ & 27,5 \\
\hline
\end{tabular}

Utiliza-se a Tabela 2 para o cálculo anual do imposto de renda pessoa física; a Tabela 3 refere-se ao mês de fevereiro de 2006, sendo aplicada para as pessoas que têm seu imposto de renda retido na fonte. 


\section{Breves considerações sobre o princípio da capacidade contributiva}

\subsection{Noção de princípio jurídico}

Os princípios são o ponto de partida do ordenamento jurídico. Este é formado por um conjunto de normas organizadas hierarquicamente, formando uma pirâmide jurídica. As normas inferiores buscam sua validade nas normas que lhes são superiores devendo estar de acordo com as mesmas, sob pena de perderem a qualidade de válidas, não produzindo efeitos de direito.

A Constituição Federal encontra-se no ápice dessa pirâmide, dando fundamento de validade as normas que estão abaixo dela. As normas que dela emanam submetem todos os todos os componentes do Estado, inclusive os Poderes Legislativo, Judiciário e Executivo. Dentro da própria Constituição existe uma hierarquia entre as normas que ela alberga. Algumas dessas normas veiculam simples regras, enquanto outras trazem verdadeiros princípios.

A palavra princípio significa fundamento, início, base, origem. No entender de Roque Antonio Carraza (2005, p. 39),

[...] um princípio jurídico e um enunciado lógico, implícito ou explicito, que, por sua grande generalidade, ocupa posição de preeminência nos vastos quadrantes do Direito e, por isso mesmo, vincula, de modo inexorável, o entendimento e a aplicação das normas jurídicas que com ele se conectam.

Geraldo Ataliba (apud CASTILHO, 2002, p. 65), com a clareza que the é peculiar, ensinava que os princípios constitucionais são de vital importância para o ordenamento jurídico, porque são eles que lhe dão a base de sustentação. Ademais, segundo o eminente mestre, a Carta de 1988 escolheu dois importantes princípios fundamentais, dos quais emanam todos os outros: o princípio republicano e o princípio federativo.

Desse modo, a Constituição Brasileira não é um conjunto de normas desconexas, mas sim um conjunto de elementos coesos, integrados, coordenados, sendo os princípios que o elemento que promove a liga entre as normas constitucionais. Além de função, os princípios, ainda, funcionam tal qual uma bússola, guiando o legislador na elaboração das normas infraconstitucionais. 
Os princípios são, portanto, normas gerais que servem de guia, de orientação, de norte, para o legislador infraconstitucional, que, ao elaborar uma norma, deverá prestar particular atenção aos princípios constitucionais, zelando por não ofendê-los, sob pena de tal norma ser rejeitada pelo sistema, que é um todo coerente e harmônico (CASTILHO, 2002, p. 68).

\subsection{O embasamento constitucional do princípio da capacidade contributiva}

A Constituição é a norma que se encontra no ápice de nosso ordenamento jurídico e, em conseqüência, orienta todos os ramos do Direito. Em se tratando de impostos enquanto espécie do gênero tributos, a Constituição de 1988, em seu artigo 145, parágrafo 1ํ, da Constituição Federal dispõe, de forma expressa, que, "sempre que possível, os impostos terão caráter pessoal, sendo graduados, em qualquer caso, segundo a capacidade econômica do contribuinte".

Diante disso, não resta dúvida de que a norma acima revela a capacidade contributiva como um verdadeiro princípio informador dos impostos. A letra do artigo em análise agiu com acerto ao não mencionar que os tributos, mas sim os impostos devem obedecer ao princípio da capacidade contributiva.

Isso se deve porque ao mencionarmos a palavra tributo, estamos tratando não só da espécie impostos, mas também das taxas. Estas, ao revés, são regidas segundo o princípio da retributividade, ou seja, o contribuinte retribui pecuniariamente o serviço público ou as diligências que levam ao ato de polícia que o alcança, pagando a exação devida. $O$ valor da taxa deve, portanto, corresponder ao custo da atuação estatal.

Carrazza (2005, p. 100-101) salienta que a expressão sempre que possível presente no texto constitucional, na verdade, não é uma mera recomendação ou um simples apela ao legislador ordinário. Na verdade, o princípio da capacidade contributiva deve ser obedecido, sempre que a regra-matriz traçada na Carta Magna Iho permitir. A maioria dos impostos, portanto, deve observar o princípio da capacidade contributiva. Entretanto, existem alguns como o ICMS, pois neste imposto a carga tributária não é suportada pelo contribuinte (comerciante, industrial ou produtor que realizou a operação mercantil), pois este a repassa para o consumidor final. Tal carga será a mesma para todos os consumidores, independentemente de sua capacidade contributiva. 
A graduação dos impostos de acordo com a capacidade econômica é um corolário do princípio da igualdade. Esta decorre do princípio federativo adotado pela República Federativa do Brasil.

Segundo Hugo de Brito Machado (1989, p. 46), "a capacidade contributiva é um critério de valoração do princípio da isonomia, e um critério capaz, a nosso ver, de realizar o princípio da Justiça".

A igualdade, em sentido econômico, significa a distribuição da carga tributária em função da capacidade contributiva. Os impostos não podem ser graduados de igual maneira, ou seja, no mesmo montante, para todas as pessoas. Isso se deve porque nem todos têm o mesmo grau de riqueza ou pobreza dentro de uma sociedade. Isso se torna mais evidente em um Estado como o brasileiro que possui uma péssima e injusta distribuição de renda entre seus cidadãos.

O princípio da capacidade contributiva importa, ainda, na vedação ao confisco, presente no artigo 150, IV, que proíbe que a União, os Estados, o Distrito Federal e os Municípios utilizem os tributos com efeito confiscatório, do artigo 5으, inciso XXII, que garante a todos o direito de propriedade e, também, do inciso LIV, do mesmo artigo 5으, que garante que "ninguém será privado da liberdade e de seus bens sem o devido processo legal."

\subsection{A capacidade contributiva aplicada ao imposto de renda pessoa física}

O Brasil é um Estado que adotou o critério da progressividade para nortear o imposto sobre a renda e proventos de qualquer natureza.

As Constituições mais recentes, em geral, prevêem a distribuição dos impostos em proporção às possibilidades econômicas, ou seja - como se costuma dizer -, com base na capacidade contributiva. Algumas delas prescrevem que o sistema tributário deve ser informado pela progressividade (UCKMAR, 1999, p. 80).

Como foi dito anteriormente, o art. 153, parágrafo 2으, inciso I, da Constituição Federal prevê que "o imposto previsto no inciso III (imposto sobre a renda e proventos de qualquer natureza) será informado pelos critérios da generalidade, da universalidade e da progressividade, na forma da lei." 
Como brilhantemente leciona Carrazza (2005, pp. 114-115), a norma existente no mencionado dispositivo é de natureza cogente, ou seja, de observância obrigatória. A lei mencionada na parte final do mesmo deverá regular o modo pelo qual se dá a progressividade, mas, em hipótese alguma poderá anular essa exigência constitucional. De igual modo, a lei em questão não poderá abolir os critérios da generalidade e da universalidade.

A fim de que um imposto de renda obedeça ao princípio da capacidade contributiva, é mister que o mesmo seja progressivo. A progressividade do imposto existe para dar eficácia ao princípio do Estado Democrático de Direito, entre cujos objetivos encontram-se a solidariedade e a redução das desigualdades sociais.

No caso do IRPF a progressividade se traduz na seguinte fórmula: quem tem rendimentos mais expressivos deve proporcionalmente ser mais tributado, do que quem tem rendimentos menores. Em outros termos, a progressividade consiste "na aplicação de alíquotas diferenciadas, que se tornam mais elevadas na medida em que se aumenta a base imponível" (CASTILHO, 2002, p. 93).

A progressividade convive diretamente ligada ao critério quantitativo da norma jurídica tributária. Este é formado por dois elementos, quais sejam, a base de cálculo e a alíquota. "No imposto sobre a renda a progressividade exterioriza-se pela aplicação de alíquotas mais elevadas às faixas mais elevadas de renda tributável" (LOURENÇO; LACOMBE, 2000, p. 42.).

Com propriedade, Aires Barreto (1998, pp. 54 e 128) assevera que a alíquota não é uma fatia ou fração da base imponível, mas um critério para a aferição da dívida tributária. São, pois, progressivas as alíquotas que aumentam na medida que cresce a base de cálculo.

É imperioso lembrar que a progressividade não pode ser confundida com a proporcionalidade. Embora ambas estejam ligadas à base de cálculo e à alíquota, são classificações diametralmente opostas.

Atualmente temos duas categorias de contribuintes do IRPF: 1) os que estão submetidos a uma alíquota de $15 \%$ e 2 ) os que se submetem a uma alíquota de $27,5 \%$. Para saber qual alíquota será aplicável em cada caso concreto, deve-se levar em conta o total de rendimentos líquidos auferidos pelo contribuinte. 
Este sistema de duas alíquotas é amplamente criticado por não concretizar efetivamente o princípio da capacidade contributiva. Como veremos, a classe média é tributada com a mesma alíquota de $27,5 \%$ que as pessoas que pertencem a uma classe que aufere rendas mais elevadas. Em termos práticos, uma pessoa que aufere $\mathrm{R} \$ 3.000,00$ mensais é tributado pela alíquota de $27,5 \%$, assim como o contribuinte que percebe $\mathrm{R} \$$ $30.000,00$ por mês. Isso é uma visível afronta ao princípio da isonomia, pois o Fisco trata de forma igual pessoas totalmente desiguais.

Carrazza (2005, p. 117) que afirma que o modelo de duas alíquotas atende, quando muito, uma progressividade parcial, e que seria necessário aperfeiçoá-lo com o aumento das faixas isentivas e a criação de um número maior de alíquotas. Em termos de comparação, o Brasil possuía, no exercício fiscal de 1986, 12 faixas que variavam de 5\% a 60\% e, a partir de 1997, restaram apenas duas, sendo que a alíquota mínima foi elevada para 15\% e a máxima reduzida para $25 \%$.

A despeito disso, para que a progressividade realmente se efetive, é preciso que a legislação autorize às pessoas que auferem rendimento, deduções, a fim de lhes garantir a sua subsistência e de seus dependentes (CARRAZZA, 2005, p. 118). Através da aplicação em conjunto da base de cálculo, da alíquota e da parcela a deduzir é que se possibilita a progressividade do atual imposto de renda pessoa física.

Na verdade, nossa legislação autoriza deduções com educação, instrução, saúde etc., porém, os valores dedutíveis estão muito aquém em relação aos gastos feitos na prática. É bem verdade que a Constituição garante a todos o direito à educação, à saúde, à moradia entre outros direitos sócias. Contudo, na prática, verificamos que tais direitos não são implementados ou, quando o são, deixam a desejar, ficando distantes de atingir o ideal de condições para promover a sobrevivência digna dos cidadãos.

\section{Conclusão}

Como vimos, o imposto de renda pessoa física é um tributo que deve, imperiosamente, obedecer ao princípio da capacidade contributiva. Este se manifesta através do sistema de alíquotas progressivas, as quais vão aumentando conforme aumenta a base de cálculo. 
Além do binômio base de cálculo e alíquota, para que o critério da progressividade realmente se implemente e proporcione um imposto mais justo para os contribuintes, é mister que possam ser feita algumas deduções que poderão ser abatidas da base de cálculo. Estas deduções envolvem gastos relacionados com o sustento e sobrevivência do contribuinte e de sua família, como, por exemplo, despesas com instrução, médicos, dentistas, pensões alimentícias, etc.

As deduções são importantes para implementar o princípio da capacidade contributiva. Através delas, o Estado deixa de tributar o mínimo vital necessário para a sobrevivência digna das pessoas.

\section{Referências}

BARRETO, Aires. Base de cálculo, alíquota e princípios constitucionais. 2. ed. São Paulo: Max Limonad, 1998.

CARRAZZA, Roque Antônio. Curso de direito constitucional tributário. 21. ed. São Paulo: Malheiros, 2005.

CARVALHO, Paulo de Barros. Curso de direito tributário. 17. ed. São Paulo: Saraiva, 2005.

CASTILHO, Paulo César Baria de Castilho. Confisco tributário. São Paulo: Editora Revista dos Tribunais, 2002.

COSTA, Regina Helena. Princípio da capacidade contributiva. 3. ed. rev. e ampl. São Paulo: Malheiros, 2003.

LOURENÇO, Américo; LACOMBE, Masset. Princípios constitucionais tributários. 2. ed. São Paulo: Malheiros, 2000.

MACHADO, Hugo de Brito. Os princípios jurídicos da tributação na Constituição de 1988. São Paulo: Editora Revista dos Tribunais, 1989.

UCKMAR, Victor. Princípios comuns de direito constitucional tributário. 2. ed. rev. e atual. conforme a 2. ed. italiana. São Paulo: Malheiros, 1999. 
Revista de Direito Público, Londrina, v. 2, N. 2, P. 177-188, MAio/Ago. 2007. 